\title{
Deposition of terrigenous sediment on subtidal marine macrobenthos: response of two contrasting community types
}

\author{
Andrew M. Lohrer*, Simon F. Thrush, Carolyn J. Lundquist, Kay Vopel, \\ Judi E. Hewitt, Phillipa E. Nicholls
}

National Institute of Water \& Atmospheric Research, PO Box 11-115, Hillcrest, Hamilton 2001, New Zealand

\begin{abstract}
Changes in patterns of land-use associated with human population growth throughout the world have altered the regime of terrigenous material export from catchments to rivers and, subsequently, to estuarine and marine communities. Although terrigenous sediment is now widely recognised as a disturbance agent in estuarine and marine communities, experimental studies on its impacts in subtidal habitats are rare. Terrigenous deposits in the intertidal zone de-water at low tide and are subjected to erosion by waves during emersion, so experimental results in spatially widespread subtidal habitats where these processes are muted may differ substantially. We deposited terrigenous sediment into replicate experimental plots at $6 \mathrm{~m}$ depth at 2 subtidal sites, creating 3 treatment levels (magnitudes of terrigenous material addition) inside and outside a small harbour in northern New Zealand. We tracked the persistence of the terrigenous deposits (3 and 7 mm thickness) over time and sampled macrobenthic communities at both sites on Days 7, 14 and 30, to compare and contrast their responses relative to controls. The diverse coarse sand community outside the harbour (Site MI) was more sensitive to terrigenous materials than that which lived in muddier sediments inside the harbour (Site TK), as indicated by multivariate and univariate analyses: both the 3 and $7 \mathrm{~mm}$ treatments caused significant change at Site MI, whereas only the more severe $7 \mathrm{~mm}$ treatment caused significant change at Site TK. The terrigenous sediments we added matched the grain size of Site TK sediments better, and macrobenthic animals living in turbid tidal estuaries are probably better conditioned to cope with high suspended sediment concentrations and sediment deposition rates. However, beyond a critical threshold, terrigenous sediment had a negative influence on communities at both sites, and they had not recovered by the time the experiment was terminated $30 \mathrm{~d}$ later.
\end{abstract}

KEY WORDS: Terrigenous sediment deposition - Subtidal marine macrobenthos · Disturbance Recovery

\section{INTRODUCTION}

Subtidal sand and mud habitats cover about $70 \%$ of the marine seafloor and dominate the seabed in many estuaries and coastal embayments (Snelgrove 1999). Such habitats can be rich and diverse, and often host key species that enhance biodiversity and the functioning of ocean ecosystems (Gray 1997). Many commercially harvested species depend directly or indi- rectly on healthy soft-sediment systems for food and shelter, and sediments are important to nutrient budgets and the global carbon cycle (Thrush \& Dayton 2002, Lohrer et al. 2004a).

Although marine sediments naturally contain particles of terrestrial origin, sudden deposits of terrigenous material can harm coastal benthic communities (McKnight 1969, Peterson 1985, GESAMP 1994, Shaffer \& Parks 1994, Ellis et al. 2000, Thrush et al. 2004). Pat- 
terns of sediment delivery from land to sea are dependent on many factors: climate, topography and land-use are among the most influential. Importantly, sediment delivery is typically pulsed and correlated with storm events (Hicks 1994, Hicks et al. 2000). Terrigenous sedimentation events pre-date humans, but human land-use practices have affected the regime of terrigenous sediment disturbance in many coastal systems (Griffiths \& Glasby 1985, Davies \& Nelson 1993, Cundy et al. 1998). Under these disturbance regimes, species must cope with increased suspended sediment loads and increased accumulations of sediment per storm, as well as the concomitant longer-term changes in habitats and the quantity and characteristics of suspended sediment. The significant broad-scale threat is that critical thresholds for benthic species are probably exceeded with increased frequency, meaning less time for recovery between events and more chance for gradual degradations in benthic community structure and function.

With this in mind, a series of studies was designed to predict the effects of increased terrigenous sediment deposition (Ellis et al. 2002, Norkko et al. 2002, Cummings et al. 2003, Hewitt et al. 2003, Thrush et al. 2003, Lohrer et al. 2004b). First, catastrophic events were simulated in experimental plots that were covered with $10 \mathrm{~cm}$ of terrigenous sediment (Norkko et al. 2002, Cummings et al. 2003). The deposits smothered and killed all macrofauna in the underlying sediment. Recolonisation and recovery was slow, and was mediated in part by crabs that could burrow into and break apart the terrigenous material. Subsequent experiments focused on thinner deposits (Lohrer et al. 2004b). Although deposits $<1 \mathrm{~cm}$ thickness did not completely defaunate the plots, macrobenthic community structure changed relative to controls and deposition events repeated at monthly intervals caused cumulative negative impacts.

Most of the investigations undertaken to date have focused on intertidal sand and mud flat communities. These locations were chosen because of their proximity to the source of terrigenous sediment, and due to the need to address site-specific questions. However, terrigenous material deposits are not confined to intertidal areas alone; terrigenous sediment is regularly transported to adjacent subtidal habitats, outside estuaries and to the continental shelf. Wheatcroft (2000) has documented sediment deposits of recent terrestrial

origin across a spatially extensive portion of the Californian continental shelf $(30 \mathrm{~km} \times 8 \mathrm{~km})$, and similar phenomena have been recorded off New Zealand (Foster \& Carter 1997) and at the mouth of the Po River in Italy (Hunt 2002). Therefore, it is important to examine the behaviour of terrigenous deposits, and the responses of organisms to them, in subtidal soft-bottom habitats.

Here, we report on a study of 2 subtidal communities threatened by sediment runoff associated with urban expansion north of Auckland, New Zealand. The sites contained an array of sessile and mobile fauna, and supported ecologically and economically important species, such as heart urchins, horse mussels, sponges, scallops, shrimps and snapper. At each site, we deposited thin layers of terrigenous sediment in experimental plots, tracked the persistence of these deposits over time and quantified their effects on macrobenthic community structure. Macrofauna were sampled on 3 occasions following terrigenous sediment application, in order to assess the immediate effects on benthic organisms and the early phases of recovery.

We made specific predictions about deposit persistence and macrofaunal response based on differing site and community characteristics. The first site, MI, 
was located off Motuketekete Island, at the mouth of Kawau Bay (Fig. 1). The second site, Site TK, was located in Te Kapa Inlet inside a tidal estuary (isohaline, salinity > $33 \mathrm{ppt}$ ). Site MI can occasionally receive choppy waves, but tidal currents are much weaker than those at Site TK. In calm weather conditions, we expected (1) terrigenous deposits to disappear more quickly at Site TK, as strong tidal currents can advect seabed sediments and potentially remove and/or bury terrigenous layers. With terrigenous layers dispersed more quickly at Site TK, (2) disturbance intensity would be reduced relative to Site MI. Furthermore, seabed sediments at Site TK are finer and suspended sediment loads are higher, so we expected (3) benthic organisms at Site TK to possess some degree of tolerance to the movement and deposition of fine sediments. Thus, we hypothesised that (4) the magnitude of response of the Site MI community would be greater than that of the Site TK community.

\section{MATERIALS AND METHODS}

Terrigenous sediment. One cubic metre of soil was collected from a coastal catchment upslope of the study sites. The soil was the same colour and consistency as terrigenous materials that typically flow into Mahurangi Harbour and Kawau Bay. The dry soil was broken apart and then mixed with seawater in concrete mixers. After thorough stirring and mixing, it was passed through a 1 to $2 \mathrm{~cm}$ mesh sieve and stored in a large vat. About $675 \mathrm{l}$ of sediment-seawater slurry was prepared, at a ratio of dry soil to seawater of approximately 1:3.

Sediment-seawater mixtures can be acidic (Cummings et al. 2003), and the slurry described here had an initial $\mathrm{pH}$ of 2.9. To buffer the slurry, $2 \mathrm{~kg}$ of sodium hydroxide $(\mathrm{NaOH})$ was dissolved in seawater and added to the vat $3 \mathrm{~d}$ prior to the start of the experiment. The $\mathrm{pH}$ of the solution was neutral after $\mathrm{NaOH}$ addition and vigorous stirring, but the ions continued to react over the next $2 \mathrm{~d}$. The $\mathrm{pH}$ of the sediment slurry was 5.6 when the final measurements were taken, about $3 \mathrm{~h}$ prior to the start of the experiment.

Experimental arrays. A mooring was established at each site, becoming the centre of a system of labelled ground lines leading to experimental plots and oceanographic instruments. At both sites, experimental arrays were arranged as in Fig. 2, with the predomi- nant current direction incorporated into the design. This set-up remained in place for $30 \mathrm{~d}$, with experiments at each site running concurrently (starting 17 February 2003 at Site MI, 18 February 2003 at Site $\mathrm{TK}_{\text {; }}$ summer water temperatures of ca. 20 to $22^{\circ} \mathrm{C}$ ). Water depth at the sites was about $6 \mathrm{~m}$, with a tidal range of $\sim 2 \mathrm{~m}$.

Circular experimental plots (diameter $1.6 \mathrm{~m}$ ) were established at the ends of the perpendicular ground lines (Fig. 2). A weighted metal ring, pressed into the sediment, delineated the circumference of each plot. Attached to the metal ring was plastic sheeting, which was gathered together to form the point of a cone. Thus, with the metal ring embedded into the sediment, a cone of water above $2 \mathrm{~m}^{2}$ of seafloor was sealed inside plastic. Known quantities of sediment slurry preparation could then be introduced through the hole at the cone's point, allowing the terrigenous material to settle out uniformly in a confined location.

To achieve terrigenous sediment deposits of 3 and $7 \mathrm{~mm}$ thickness, 24 and $56 \mathrm{l}$ of slurry were introduced, respectively. The mixture dispersed rapidly inside the plastic cones and settled evenly over the areas intended for treatment. There were 4 plots of each treatment type.

The cones and rings were left in place for about $2 \mathrm{~h}$, to allow the terrigenous particles to settle out. Divers slowly lifted the cones and rings, leaving circular patches of yellow-orange terrigenous material. According to our calculations, we introduced the proper amount of slurry to produce 3 and $7 \mathrm{~mm}$ layers of dry, de-watered soil (similar to the thin layers deposited previously in intertidal habitats; Lohrer et al. 2004b). Here, in the subtidal, however, the sediment-slurry remained in a

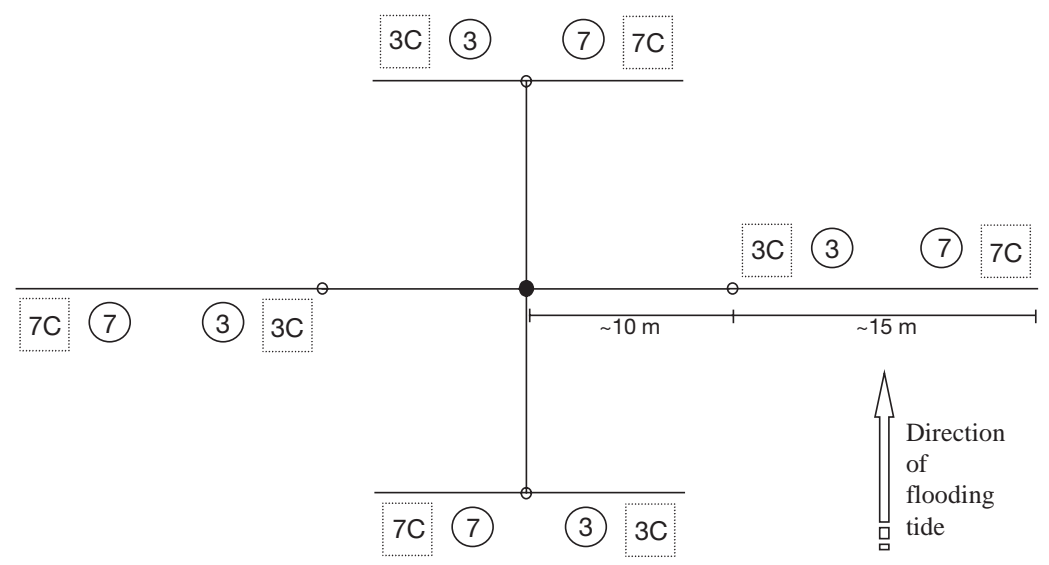

Fig. 2. Plan view of the experimental array established at $\sim 6 \mathrm{~m}$ depth at each subtidal site (i.e. Site MI in Kawau Bay and Site TK in Mahurangi Harbour). Ground lines (10 m length) extended outward from a central mooring in 4 directions. Additional lines led to experimental plots. Each plot that received terrigenous sediment (circles, marked 3 or 7 in reference to millimetre thickness) was paired with a control area (squares, marked $3 \mathrm{C}$ or $7 \mathrm{C}$ ) 
fluid state, resulting in deposits of approximately 10 and $20 \mathrm{~mm}$ for the 2 treatments, respectively.

Control areas (no sediment added) were also recognised, and separate controls were maintained for each type of treated plot (i.e. 3 and $3 C_{i} 7$ and 7 C) (Fig. 2). There were no rings or definite boundaries for the control areas; samples were collected haphazardly from areas several metres away from the nearest treated plot. Since current direction was incorporated into the experimental design, control areas were not likely affected by terrigenous sediment moving laterally out of treated plots nearby (Fig. 2).

An electromagnetic current metre (InterOcean S4a) measured current speed and direction at each site $(20$ data burst averages $\mathrm{h}^{-1}$ for $30 \mathrm{~d}$, measured $\sim 50 \mathrm{~cm}$ above the bed). Four DOBIE wave gauges with optical backscatter sensors quantified water depth, significant wave height $\left(H_{\text {sig }}\right)$, orbital bed velocity $\left(U_{\text {sigb }}\right)$ and suspended sediment concentrations (SSC) over the same time interval ( 7 min data bursts at $5 \mathrm{~Hz}$ every $20 \mathrm{~min}$, measured $\sim 15 \mathrm{~cm}$ above the bed).

Sediment grain size and organic matter content. To characterise how the sedimentary environment changed at each site following the application of terrigenous material, sediment samples were collected at 5 intervals during the experimental period. Two plastic vials of surficial sediment (to a depth of $2 \mathrm{~cm}$ ) were collected from each treated plot and adjacent control on Days 1, 3, 7, 14 and 30. Day 1 samples were collected $<1 \mathrm{~h}$ after the plastic application cones were lifted away from the treated plots. All samples were frozen and kept in the dark until analysis.

Organic matter content was calculated from loss on ignition (LOI, i.e. by the percent change in mass of sediment after drying at $60^{\circ} \mathrm{C}$ for $48 \mathrm{~h}$ and combusting in a muffle furnace for $5.5 \mathrm{~h}$ at $400^{\circ} \mathrm{C}$ ).

For particle size analysis, a $9 \%$ solution of hydrogen peroxide was added to the vials of sediment to remove organic matter. After $48 \mathrm{~h}$, the percent volumes for 11 different grain size categories were determined with a Galai particle analyser (Galai Cis-100; Galai Productions).

Macrobenthic infauna. To assess macrobenthic community structure, 1 core $(10 \mathrm{~cm}$ internal diameter, $13 \mathrm{~cm}$ deep) was taken on each of 3 dates, from every plot, at each site. Cores on Day 7 were collected to assess the effect of terrigenous sediment deposition, whereas cores on Days 14 and 30 were taken to assess the trajectory of recovery following the initial impacts. Different sectors of the circular plots were sampled on each date to avoid undesired re-sampling effects. We also avoided edge effects by collecting samples $>30 \mathrm{~cm}$ from plot boundaries.

Macrofaunal samples were sieved on $0.5 \mathrm{~mm}$ mesh, preserved in $70 \%$ isopropyl alcohol and stained with $0.2 \%$ Rose Bengal. Macrofauna were sorted and iden- tified to the lowest taxonomic level practicable (mostly to species level, although we could not name all species definitively).

Statistical analysis. A variety of univariate and multivariate statistical techniques was used to characterise the response of macrofauna to the experimental addition of terrigenous sediment. The percent similarity among samples in various treatments was computed using PRIMER 5.0 (Clarke \& Gorley 2001). Bray-Curtis similarity matrices were created from untransformed macrofaunal community datasets, and variation in macrofaunal community structure was assessed visually using multi-dimensional scaling (MDS). Statistical comparisons among treatments and tests of macrobenthic community recovery between sampling dates were performed with a non-metric multivariate analysis of variance program (NP-MANOVA) (Anderson 2001). Following an initial impact (i.e. significant differences between treatments and controls), subsequent increases in the similarity of treated and control communities would be indicative of recovery. Differences in the magnitude of effect related to the day of sampling would result in significant treatment $\times$ day interactions. The NP-MANOVA program generates probabilities for main effects and interaction terms, allowing us to evaluate recovery between Days 7 and 30 by estimating the significance of treatment $\times$ day interactions.

Differences with respect to site, date and treatment were assessed for variables such as the total number of individuals and taxa per sample, the Shannon-Wiener diversity index and the densities of several common species from each site. An a priori decision was made to analyse data from the 2 sites separately, because the physical and biological attributes of each site differed greatly and because the 2 sites had few macrofaunal species in common. Furthermore, to help reduce the effects of within-site spatial heterogeneity in our treatment-control comparisons, we used Wilcoxon 2-sample tests on the treatment-control pairs shown in Fig. 2. This non-parametric test uses rank scores based on differences between paired samples; it is more powerful than parametric tests when assumptions of normality and homogeneity of variance cannot be satisfied (which was the case for most of the individual species analyses). Tests of the null hypothesis (control-treatment differences are less than or equal to zero) were 1 -tailed with $\alpha=0.05$.

\section{RESULTS}

\section{Physical data and other observations}

During the first week of the experiment, weather conditions were calm. At both sites, the average significant wave height (based on the largest $1 / 3$ of wave heights 
recorded) was $<5 \mathrm{~cm}$. Energy from waves of this size did not penetrate to the bed (orbital bed velocity $<2.5 \mathrm{~cm} \mathrm{~s}^{-1}$ ). A storm event that peaked on Days 7 and 8 increased wave heights. Resultant orbital bed velocities were $>25 \mathrm{~cm} \mathrm{~s}^{-1}$ at Site TK, but $<15 \mathrm{~cm} \mathrm{~s}^{-1}$ at Site MI.

The suspended sediment concentration (SSC) increased during the storm at both sites and was elevated for about $3 \mathrm{~d}$. Maximum concentrations during the storm were around $150 \mathrm{mg} \mathrm{l}^{-1}$ at Site TK and about $20 \mathrm{mg} \mathrm{l}^{-1}$ at Site MI. In calm conditions, SSC values at Site TK ranged from 0 to $15 \mathrm{mg} \mathrm{l}^{-1}$, with peak levels at low tide. Water is typically clear at Site MI, and no tidally correlated changes in SSC were observed during the experimental period.

With our experimental method, we created well-defined terrigenous sediment deposits on the seafloor and produced even layers of sediment across each plot. Approximately $1 \mathrm{~h}$ following application, the sedimentseawater slurry rested lightly on the seabed as cohesive liquid deposits. Small bow waves preceded hermit crabs and seastars as they moved through the fluid mixture. There were numerous instances of burrow clearing, as plumes of terrigenous sediment were seen being ejected from hole and burrow structures in the seafloor. These structures were probably occupied by fan worms, crabs, shrimps, and/or infaunal bivalves.

Some Day 3 observations suggested immediate negative impacts from terrigenous material deposition. Most noteworthy was the presence of 17 heart urchins Echinocardium australe at the surface of the experimental deposits at Site MI. All of the urchins were dead, and nearly all had large holes indicative of predation.

Other observations from Day 3 suggested the beginnings of recovery. Many of the holes and burrows were surrounded by small cones of dark marine sediment, where the inhabitants had obviously re-excavated and cleaned the terrigenous sediment from their burrows. In addition to the reworking of sediment from within plots, ambient marine silt from beyond plot boundaries was beginning to collect on top of the deposits by Day 3. Over time, plots at both sites became covered with marine sediment, although this was more rapid and extensive at Site TK. The ambient sediment layers on top of the terrigenous deposits at the end of the experiment (Day 30) were about 2 times thicker at Site TK than at Site MI $(14.4 \pm 4.0$ and $8.9 \pm 1.4 \mathrm{~mm}$, respectively; means $\pm 1 \mathrm{SE}$, $\mathrm{n}=4$ ), though at least some yellow terrigenous sediment was visible in every experimental plot.

\section{Sediment characteristics}

Ambient sediments at Site MI were dominated by coarse, fine and medium sands (250 to $1000 \mu \mathrm{m})$, whereas sediments at Site TK were dominated by very fine and fine sands (63 to $250 \mu \mathrm{m}$ ) and had greater silt content. The terrigenous sediment slurry that we applied was muddy, with $>77 \%$ of the particles $<63 \mu \mathrm{m}$ (i.e. silts and clay). Clay particles $<3.9 \mu \mathrm{m}$ comprised $9 \%$ of the material, and medium silt (15 to $32 \mu \mathrm{m}$ ) was the most common particle size category at $20 \%$. The application of this terrigenous material altered the sediment particle size distributions at each site, and the effect persisted until the end of the experiment (Day 30) at each site. Particle size distributions shifted by a larger amount at Site MI, as it had coarser ambient sediments (Fig. 3).

All main effects and first-order interaction terms were significant in our analysis of sediment organic matter content data (repeated-measures ANOVA, $\mathrm{n}_{\text {total }}=160, \mathrm{p}<0.05$ for treatment, site, day, treatment $\times$ site, treatment $\times$ day, site $\times$ day). However, plots treated with terrigenous sediment tended to have higher organic matter content than control plots, especially at Site MI (see Fig. 5). At Site TK, treated plots contained more organic matter on 4 of the 5 sampling dates, with Day 7 being the only exception (Fig. 4). The experimental terrigenous sediment itself had an organic matter content of $4.6 \%$.

\section{Response of macrofauna}

Multivariate analysis (NP-MANOVA) of data from control cores revealed differences in macrofaunal community structure with respect to site $(p=0.001)$, with an average dissimilarity between sites of $89.54 \%$. Site MI contained more individuals and more taxa per sample and was significantly more diverse (Tables 1 \& 2). Site MI was dominated by polychaetes (Table 1), whereas bivalves and small crustaceans were dominant at Site TK (Table 2).

At Site MI, effects of sampling date on macrobenthic community structure were significant in the 2-way crossed NP-MANOVA ( $p=0.018)$. Furthermore, significant differences among the experimental treatments persisted across days $(p=0.001)$, while day $\times$ treatment interaction terms were not significant $(p=0.766)$. Small polydorid, maldanid and sabellid polychaetes were common on Day 30 (>7 ind. per core, Table 1), after being relatively uncommon the previous 2 sampling dates (averaging 0 to 2 ind. per core). These maldanids and sabellids were collected in control cores only (i.e. they were absent from all sediment-treated plots, even on Day 30, when they were common in controls).

Ordination plots (MDS) of treatment mean values demonstrate the changes to macrobenthic community structure that are related to depositional thickness. At Site MI (Fig. 5), both types of treated plots were separated from controls, and this pattern was similar on all 


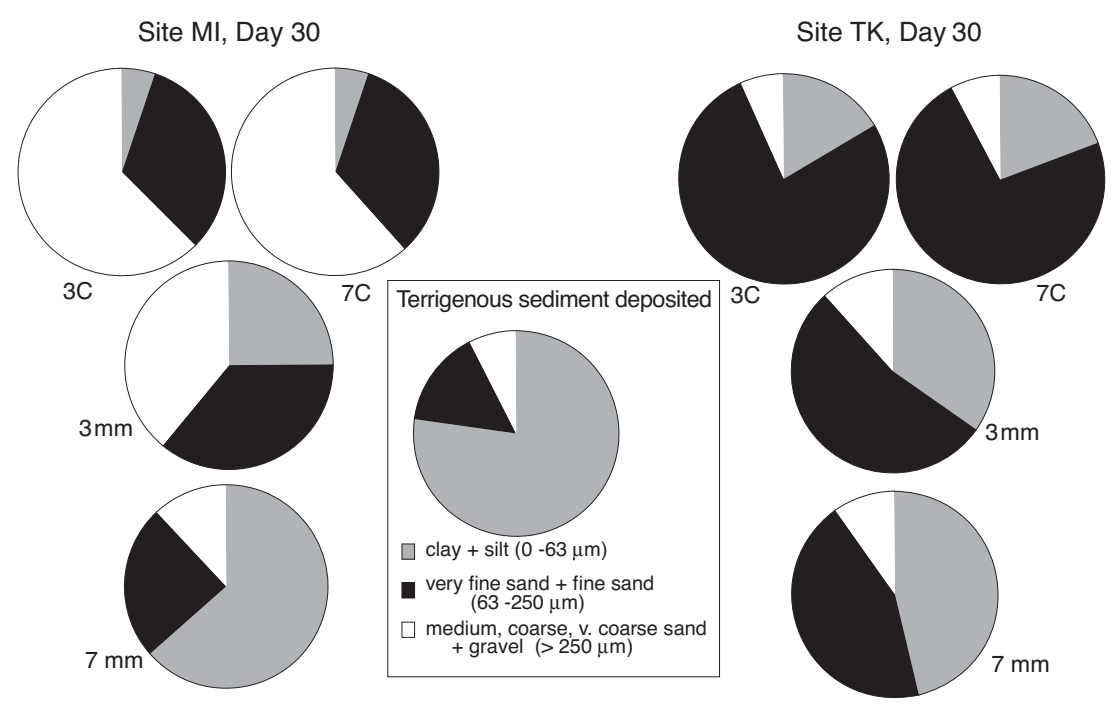

Fig. 3. Sediment particle size distribution on Day 30, in the 4 experimental treatments at each site. Each pie chart represents the average of 4 replicates

Statistical analyses of the number of individuals, number of taxa and the densities of several abundant species at each site revealed treatment effects. Note that our design allowed us to calculate the difference in abundance for every treatment-control pair (i.e. $3 \mathrm{C}-3,7 \mathrm{C}-$ 7 ). Given that the community variables (number of individuals, number of taxa, Shannon-Wiener diversity) and the multivariate analyses of community structure showed no indications of recovery (i.e. no treatment $\times$ day interactions), we pooled data across dates for our individual species analyses for greater statistical power and clarity. Figs. 7, 8, \& 9 show these treatment-control differences. At Site MI, the number of individuals and taxa (Fig. 7) and the

$3 \mathrm{~d}$. The relative distance between controls and $7 \mathrm{~mm}$ plots (in ordination space) was greater than the distance between controls and $3 \mathrm{~mm}$ plots. Although the 3 and $7 \mathrm{~mm}$ treatments were both separated from controls, only the $7 \mathrm{~mm}$ treatment differed significantly (a posteriori tests following NP-MANOVA, $\mathrm{p}=0.262$ for $3 \mathrm{C}$ vs. 3, $\mathrm{p}=0.002$ for $7 \mathrm{C}$ vs. 7).

Macrobenthic community structure at Site TK was also affected by experimental treatment $(p=0.002)$. There was an influence of date $(p=0.086)$, but no significant day $\times$ treatment interaction $(p=0.783)$. Here, however, there was little apparent effect in the $3 \mathrm{~mm}$ plots $(p=0.519)$ relative to the strong and significant effects in the $7 \mathrm{~mm}$ plots ( $\mathrm{p}<0.003$; Fig. 6). densities of 10 common polychaete and crustacean groups (Fig. 8) were all significantly reduced by the $7 \mathrm{~mm}$ terrigenous sediment treatments. The response to the $3 \mathrm{~mm}$ treatments was weaker, but still significant for Euchone, Heteromastus, Asychis, another unidentified maldanid species and the total number of individuals and taxa. At Site TK, the $3 \mathrm{~mm}$ treatment did not reduce the number of individuals or taxa (Fig. 7) or any of 5 common bivalve and crustacean groups (Fig. 9). The thicker $7 \mathrm{~mm}$ treatments at Site TK did reduce the densities of these variables, though the response was not as strong as it was at Site MI and several trends were not significant (e.g. Arthritica, Nucula and Shannon-Wiener diversity).
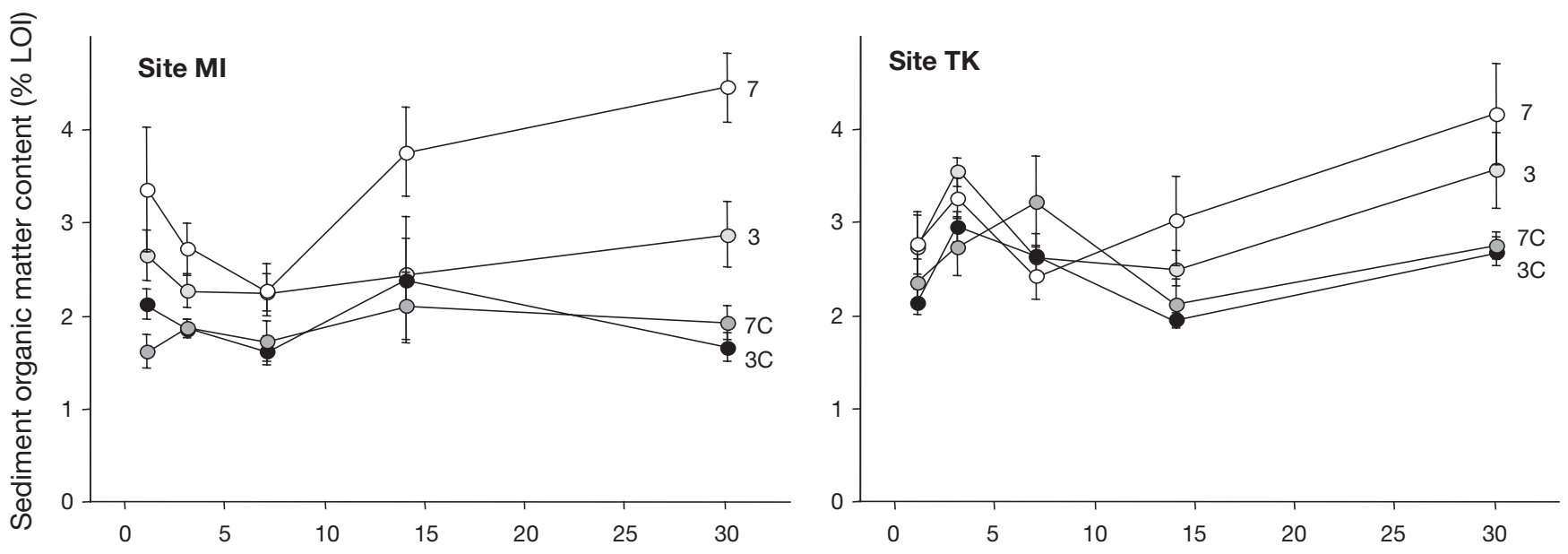

Days after terrigenous sediment application

Fig. 4. Sediment organic matter content (measured as percent loss on ignition, \%LOI). Mean values for each treatment $( \pm 1 \mathrm{SE}$, $\mathrm{n}=4$ ) are given for each date at each site. Sediments from treated plots tended to have a greater content of organic matter 
Table 1. Abundance of macrofauna in control cores at Site MI on 3 sample dates (mean $\pm \mathrm{SE} ; \mathrm{n}=8$ ). Taxa with an average of $<1$ individual per core are not listed. B: bivalve; A: amphipod; C: cumacean; P: polychaete

\begin{tabular}{|c|c|c|c|c|c|c|}
\hline & Day 7 & & Day 14 & & Day 30 & \\
\hline 1 & Exogonid $(\mathrm{P})$ & $32.0 \pm 9.4$ & Exogonid $(\mathrm{P})$ & $29.8 \pm 5.8$ & Exogonid $(\mathrm{P})$ & $57.4 \pm 20.5$ \\
\hline 2 & Maldanid, Asychis (P) & $17.8 \pm 6.4$ & Maldanid, Asychis (P) & $25.3 \pm 6.2$ & Maldanid, Asychis (P) & $16.0 \pm 3.7$ \\
\hline 3 & Chaetopterid $(\mathrm{P})$ & $10.3 \pm 6.4$ & Chaetopterid (P) & $10.6 \pm 3.8$ & Polydorid spp. (P) & $8.4 \pm 2.5$ \\
\hline 4 & Heteromastus $(\mathrm{P})$ & $5.8 \pm 1.0$ & Phoxocephalidae (A) & $5.4 \pm 1.6$ & Ostracoda & $8.4 \pm 3.3$ \\
\hline 5 & Phoxocephalidae (A) & $4.9 \pm 1.1$ & Ostracoda & $5.1 \pm 1.9$ & Sabellid (P) & $7.9 \pm 4.5$ \\
\hline 6 & Tanaidacea & $4.1 \pm 1.3$ & Tanaidacea & $3.8 \pm 1.7$ & Heteromastus (P) & $7.5 \pm 0.9$ \\
\hline 7 & Euchone $(\mathrm{P})$ & $3.9 \pm 1.5$ & Heteromastus $(\mathrm{P})$ & $3.5 \pm 0.7$ & Maldanid sp. (P) & $7.3 \pm 2.9$ \\
\hline 8 & Gynodistylis (C) & $3.1 \pm 3.1$ & Eunicid sp. (P) & $3.5 \pm 1.4$ & Tanaidacea & $6.0 \pm 2.2$ \\
\hline 8 & Scoloplos $(\mathrm{P})$ & $3.1 \pm 1.1$ & Scoloplos $(\mathrm{P})$ & $2.8 \pm 1.0$ & Chaetopterid (P) & $3.6 \pm 1.6$ \\
\hline 10 & Ostracoda & $2.6 \pm 1.5$ & Euchone (P) & $2.6 \pm 1.0$ & Scoloplos (P) & $2.8 \pm 1.0$ \\
\hline 11 & Oligochaeta & $2.1 \pm 0.9$ & Maldanid sp. (P) & $1.6 \pm 0.8$ & Phoxocephalidae (A) & $2.5 \pm 1.0$ \\
\hline 12 & Polydorid spp. (P) & $2.0 \pm 1.1$ & Polydorid spp. (P) & $1.5 \pm 0.7$ & Euchone $(\mathrm{P})$ & $2.3 \pm 1.3$ \\
\hline 13 & Paraonid $(\mathrm{P})$ & $1.5 \pm 0.8$ & Gynodistylis (C) & $1.4 \pm 0.9$ & Cirratulid (P) & $2.3 \pm 0.6$ \\
\hline \multirow[t]{4}{*}{14} & Nucula hartvigiana (B) & $0.8 \pm 0.4$ & Maldanid, Macroclymenella (P) & $1.3 \pm 0.8$ & Paraonid (P) & $1.5 \pm 0.6$ \\
\hline & Total no. of individuals & $119.5 \pm 9.0$ & & $117.3 \pm 16.4$ & & $166.6 \pm 38.2$ \\
\hline & Total no. of taxa & $23.9 \pm 1.5$ & & $22.8 \pm 1.9$ & & $28.4 \pm 2.1$ \\
\hline & $\begin{array}{l}\text { Shannon-Wiener } \\
\text { diversity index }\end{array}$ & $2.37 \pm 0.10$ & & $2.35 \pm 0.10$ & & $2.54 \pm 0.08$ \\
\hline
\end{tabular}

Table 2. Abundance of macrofauna in control cores at Site TK on Days 7 and 30 (mean $\pm \mathrm{SE} ; \mathrm{n}=8$ ). Taxa with an average of $<1$ individual per core are not listed. B: bivalve mollusc; A: amphipod crustacean; C: cumacean shrimp; P: polychaete

\begin{tabular}{|llcllll}
\hline \multicolumn{2}{|c}{ Day 7} & Day 14 & Day 30 \\
\hline 1 & Theora lubrica (B) & $8.3 \pm 0.8$ & Theora lubrica (B) & $5.8 \pm 1.3$ & Theora lubrica (B) \\
2 & Ostracoda & $7.5 \pm 1.3$ & Phoxocephalidae (A) & $5.8 \pm 2.3$ & Ostracoda & $9.8 \pm 1.4$ \\
3 & Arthritica bifurca (B) & $2.5 \pm 1.3$ & Ostracoda & $4.4 \pm 1.2$ & Arthritica bifurca (B) & $2.6 \pm 2.1$ \\
3 & Nucula hartvigiana (B) & $2.5 \pm 0.6$ & Cirratulid (P) & $1.9 \pm 0.6$ & Nucula hartvigiana (B) & $2.3 \pm 0.6$ \\
5 & Phoxocephalidae (A) & $2.4 \pm 0.7$ & Arthritica bifurca (B) & $1.6 \pm 0.9$ & Cirratulid (P) & $2.1 \pm 0.6$ \\
6 & Oligochaeta & $2.0 \pm 1.2$ & Paraonid (P) & $1.6 \pm 0.4$ & Paraonid (P) & $1.1 \pm 0.4$ \\
7 & Hemileucon (C) & $1.9 \pm 0.7$ & Heteromastus (P) & $1.4 \pm 0.8$ & Phoxocephalidae (A) & $1.0 \pm 0.3$ \\
8 & Paraonid (P) & $1.4 \pm 0.5$ & Nucula hartvigiana (B) & $1.0 \pm 0.3$ & Oligochaeta & $1.0 \pm 0.3$ \\
9 & Cirratulid (P) & $0.9 \pm 0.4$ & Corophiid (A) & $0.9 \pm 0.4$ & Hemileucon (C) & $1.0 \pm 0.3$ \\
& Total no. of individuals & $34.9 \pm 3.8$ & & $34.9 \pm 4.3$ & & $33.5 \pm 2.2$ \\
& Total no. of taxa & $11.6 \pm 0.9$ & & $14.5 \pm 1.1$ & & $12.9 \pm 0.9$ \\
& Shannon-Wiener & $2.08 \pm 0.06$ & & $1.82 \pm 0.31$ & & $2.07 \pm 0.12$ \\
& diversity index & & & & \\
\end{tabular}

\section{DISCUSSION}

Similar to previous experiments in intertidal habitats, the application of terrigenous sediment significantly altered macrobenthic community structure and reduced the number of individuals and taxa present at each subtidal site. The magnitude of effects varied between Sites MI and TK, with stronger effects outside the harbour. The densities of several common species (generally polychaetes at Site MI and bivalves at Site TK) were also affected, more so in the thicker $7 \mathrm{~mm}$ plots than in the thinner $3 \mathrm{~mm}$ ones. Similar to intertidal experiments (Lohrer et al. 2004b), where a comparable thickness of terrestrial sediment was applied, total densities and densities of individual taxa changed by about $50 \%$. None of the individual taxa assessed showed consistent positive responses to the addition of terrestrial sediment, and overall there was little sign of macrobenthic community recovery during the $30 \mathrm{~d}$ experiment, with the exception of positive trends for 2 polychaete worm species at Site TK (a paraonid and a cirratulid, neither trend significant at $\mathrm{a}=0.05$ ).

\section{Site differences}

Estuaries are typically more turbid than open coastal environments. Furthermore, narrow channels and the 
overall topography of most estuaries equates to significant tidal currents, increasing the chances for sediment resuspension and bedload sediment transport. Therefore, estuarine fauna such as those at Site TK may be more conditioned to cope with sediment movement and sediment deposition than fauna in coastal habitats nearby (Site MI). In Mahurangi Harbour, suspended sediment loads control the natural distribu-

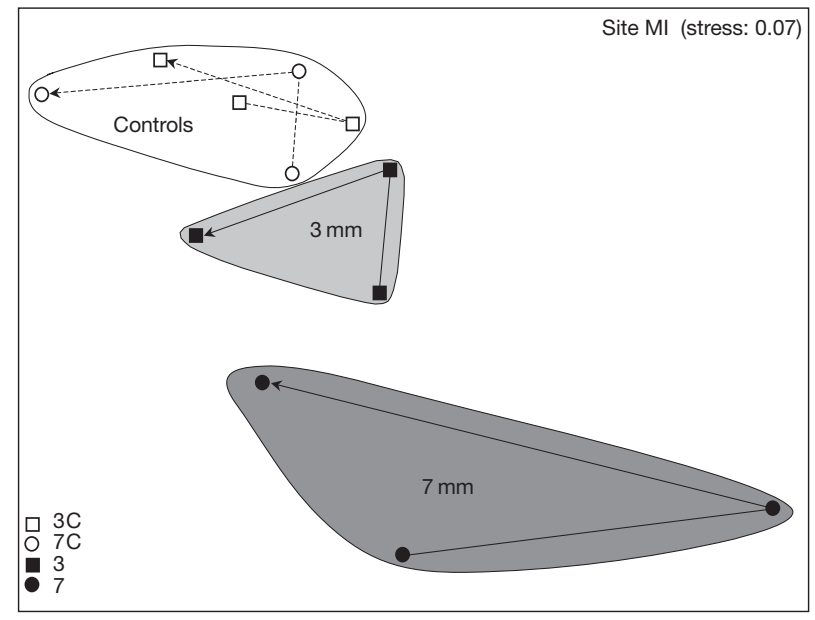

Fig. 5. Community composition and treatment effects at Site MI, depicted by non-metric multidimensional scaling. Mean community data of control plots and sediment-treated plots are displayed in 2-dimensional ordination space. The accuracy of this presentation is indicated by the low stress value $(0.07)$. The greater the distance between points in ordination space, the greater the dissimilarity in community composition. Arrows show the trajectories of change within each treatment over time, from Day 7 to Day 14 to Day 30

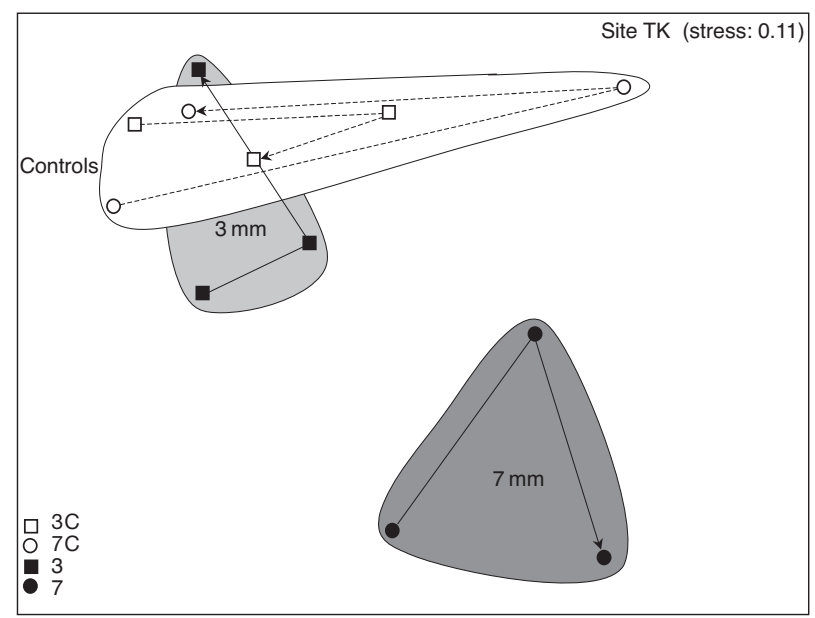

Fig. 6. Community composition and treatment effects at Site TK, depicted by non-metric multidimensional scaling. Further explanations as in Fig. 5. The accuracy of this presentation is indicated by the low stress value $(0.11)$ tional limits of at least 1 key suspension feeder (the bivalve Atrina zelandica, Ellis et al. 2002), and, although no distributional mechanisms were investigated here, there were distinct differences in the benthic communities at Sites MI and TK. The bivalves Theora lubrica and Arthritica bifurca, which were among the most abundant taxa inside the harbour at Site TK (Table 2), are known for their tolerance to muddy sediments. In contrast, sand-associated polychaetes (surface-dwelling suspension and deposit feeders) dominated the macrofauna at Site MI.

Although only 2 groups (both small crustaceans, Phoxocephalidae and Ostracoda) were sufficiently
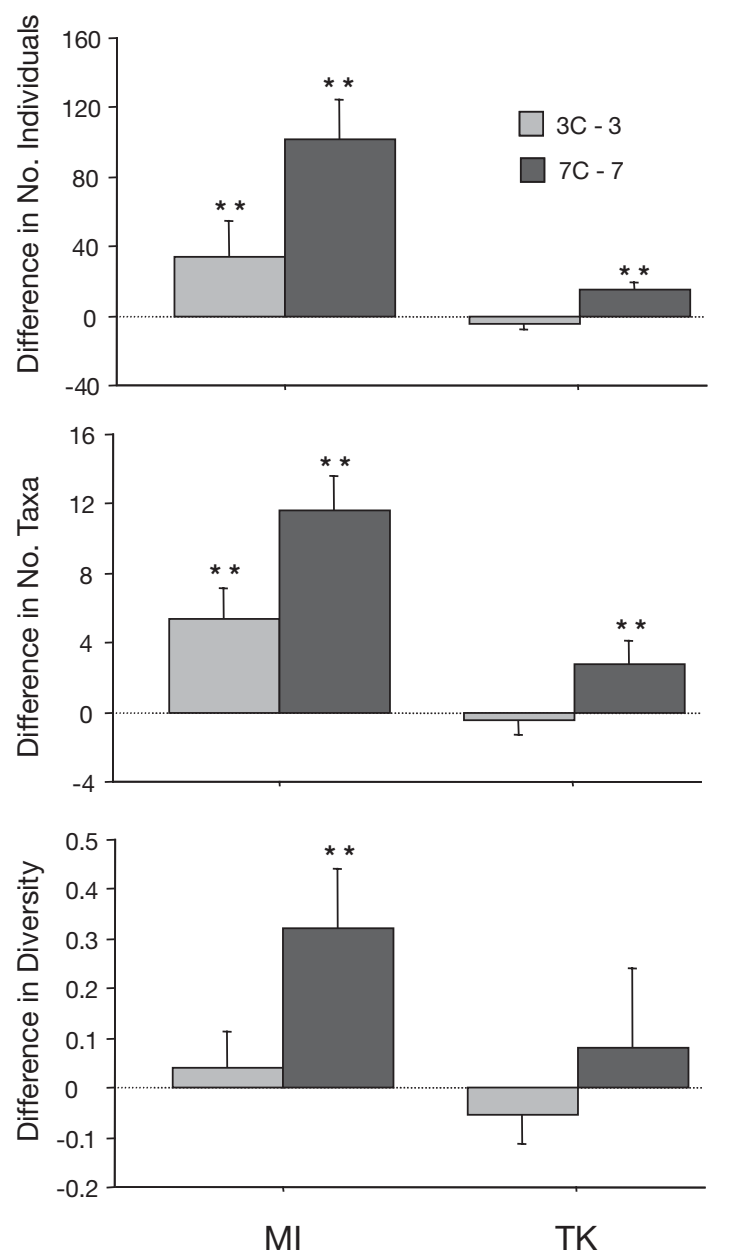

Fig. 7. Average differences between treatment and control pairs (+1 SE) for number of individuals, number of taxa and Shannon-Wiener diversity. Data from 3 dates have been pooled (see 'Results; Response of macrofauna'), thus $\mathrm{n}=12$ per average. A difference of zero indicates relative similarity between treatment and control data. Greater mean values (bar heights in the positive direction) indicate greater negative impact. These impacts are given for 3 and $7 \mathrm{~mm}$ treatments. Results of Wilcoxon 2-sample tests on the data pairs are given as asterisks and denote differences significantly greater than zero. Double asterisks are significant at $p<0.05$ 
abundant at both sites for comparative analyses, their responses were consistent across sites (Figs. 8 \& 9). Phoxocephalids declined by 27 and $35 \%$ in response to $7 \mathrm{~mm}$ treatments at Sites TK and MI, respectively. Declines for ostracods were 31 and $63 \%$. The $3 \mathrm{~mm}$ treatments did not affect phoxocephalids or ostracods at either site.
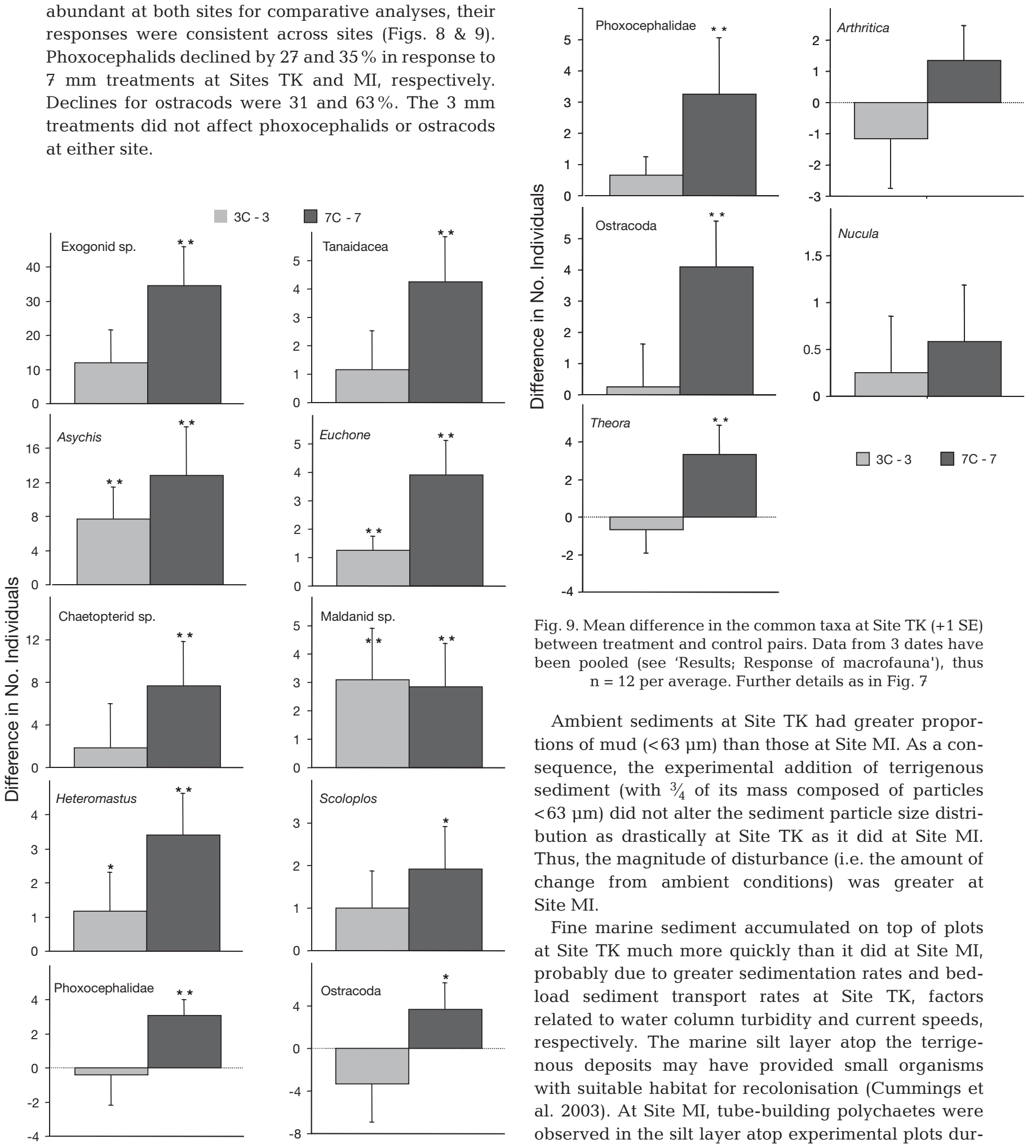

Fig. 9. Mean difference in the common taxa at Site TK (+1 SE) between treatment and control pairs. Data from 3 dates have been pooled (see 'Results; Response of macrofauna'), thus $\mathrm{n}=12$ per average. Further details as in Fig. 7

Ambient sediments at Site TK had greater proportions of mud $(<63 \mu \mathrm{m})$ than those at Site MI. As a consequence, the experimental addition of terrigenous sediment (with $3 / 4$ of its mass composed of particles $<63 \mu \mathrm{m}$ ) did not alter the sediment particle size distribution as drastically at Site TK as it did at Site MI. Thus, the magnitude of disturbance (i.e. the amount of change from ambient conditions) was greater at Site MI.

Fine marine sediment accumulated on top of plots at Site TK much more quickly than it did at Site MI, probably due to greater sedimentation rates and bedload sediment transport rates at Site TK, factors related to water column turbidity and current speeds, respectively. The marine silt layer atop the terrigenous deposits may have provided small organisms with suitable habitat for recolonisation (Cummings et al. 2003). At Site MI, tube-building polychaetes were observed in the silt layer atop experimental plots during the later part of the experiment $(9.6 \pm 3.0$ polydorids per treated plot, $8.4 \pm 2.5$ per control; mean \pm $1 \mathrm{SE}$ ). However, other polychaetes that were recruiting to control plots at the same time (sabellid and maldanid species, between Days 14 and 30) were
Fig. 8. Mean difference in the common taxa at Site MI (+1 SE) between treatment and control pairs. Data from 3 dates have been pooled (see 'Results; Response of macrofauna'), thus $\mathrm{n}=12$ per average. A single asterisk is marginally significant $(p<0.10)$. Further details as in Fig. 7 
absent from all 3 and $7 \mathrm{~mm}$ experimental plots on Day 30. Generally, with the ambient silt layer forming more quickly and more deeply at Site TK, the opportunity for macrofaunal recolonisation was probably enhanced relative to Site MI. In addition, the greater number of holes and burrows at Site TK was indicative of greater bioturbation and sediment reworking rates, another factor that may have increased the break-up of the terrigenous sediment layers and reduced the magnitude of the macrofaunal response at this site.

\section{Comparisons to previous studies: intertidal vs. subtidal experiments}

Based on previous work in intertidal environments, we knew that just a few millimetres of sediment were necessary to influence some intertidal communities, and that thick deposits were catastrophic. The results we obtained in the present study, from subtidal habitats in Mahurangi Harbour and Kawau Bay, were similar to those obtained previously in Whitford's intertidal habitats (Lohrer et al. 2004b). Again, we observed a gradient in response to terrigenous sedimentation; more sediment translated to greater effects. Those effects were manifested as fewer individual macrofauna, fewer macrofaunal taxa and reduced macrofaunal diversity.

The persistence of the terrigenous deposits also differed in intertidal and subtidal habitats. We hypothesised that the terrigenous materials might be dispersed away from the subtidal plots within hours. However, the terrigenous sediment was clearly visible $30 \mathrm{~d}$ following deposition, longer than it remained in place in the intertidal zone. Furthermore, terrigenous deposits de-water and can 'set' or harden when exposed to air on intertidal sandflats (Cummings et al. 2003), whereas the subtidal terrigenous sediment deposits of our study never fully de-watered or compacted. Burrowing animals that were covered by the terrigenous slurry began re-excavating their holes and ejecting the foreign sediment almost immediately. While some bioturbators apparently tolerated the muddy terrigenous material (Macrophthalmus hirtipes, crabs common at Site TK), other burrowing species did not fare well (e.g. Echinocardium australe, the spatangoid urchins killed at Site MI). Large bioturbating animals can have significant effects on sediment characteristics and nutrient efflux from pore waters, and losses of species such as $E$. australe could result in reduced microphytobenthic productivity and sediment organic matter content (Lohrer et al. 2004a), factors which are likely to affect macrobenthic communities.

\section{Conclusions and context}

Patterns of land use change associated with human population expansion, combined with steep catchments and a rainy climate, are increasing sediment run-off from land to sea in many parts of the world. Results from our experiments suggest that terrigenous deposits can modify the seabed's sedimentary environment and impact macrofaunal communities in subtidal habitats. The recovery from initial effects in this experiment was slow (>30 d), despite hydrodynamic influences such as tidal currents and waves that were predicted to disperse terrigenous layers and supply disturbed plots with ambient marine sediment and post-larval colonists. Small-sized deposits (such as our experimental plots) likely recover much more quickly than larger-sized disturbances because of the greater potential contribution from juvenile and adult colonists migrating in from the plot edges (Whitlatch et al. 1998), so recovery time following real terrigenous sedimentation events over broad areas of continental shelf could be quite protracted. Although terrigenous sediment deposition outside the harbour at Site MI is likely to be less frequent and of lesser magnitude than the deposition at Site TK, the threshold for significant effects on macrobenthic community structure also appears to be less. Our work thus emphasises and better characterises the considerable broad-scale threat of increased terrigenous sediment loading to the coastal marine environment in northern New Zealand and in coastal areas worldwide.

Acknowledgements. This research was funded by the Auckland Regional Council (NIWA Project ARC03205), with additional support from the New Zealand Foundation for Research Science and Technology (FRST Contract No. C01X0307). The hard work of numerous divers (R. Budd, R. Liefting, G. Funnell, P. Nicholls, A. Norkko and C. Lundquist) made the project safe and successful. L. Hunt assisted with invertebrate identifications, R. Ovendon performed grain size analysis. Many thanks to B. Thompson and C. Hatton at the $\mathrm{ARC}$ for providing resource consents and other assistance during the project. V. Cummings provided helpful comments on earlier drafts of this manuscript.

\section{LITERATURE CITED}

Anderson MJ (2001) A new method for non-parametric multivariate analysis of variance. Aust Ecol 26:32-46

Clarke KR, Gorley RN (2001) Primer v5. Primer-E, Plymouth Cummings V, Thrush S, Hewitt J, Norkko A, Pickmere S (2003) Terrestrial deposits on intertidal sandflats: sediment characteristics as indicators of habitat suitability for recolonising macrofauna. Mar Ecol Prog Ser 253:39-54

Cundy AB, Collins PEF, Turner SD, Croudace IW, Horne D (1998) 100 years of environmental change in a coastal wetland, Augusta Bay, southeast Sicily: evidence from geochemical and paleoecological studies. In: Black KS, Paterson DM, Cramp A (eds) Sedimentary processes in the 
intertidal zone, Vol 139. Geological Society Special Publications, London, p 243-254

Davies PE, Nelson M (1993) The effect of steep slope logging on fine sediment infiltration into the beds of ephemeral and perennial streams of the Dazzler Range, Tasmania, Australia. J Hydrol 150:481-504

Ellis JI, Norkko A, Thrush SF (2000) Broad-scale disturbance of intertidal and shallow sublittoral soft-sediment habitats; effects on the benthic macrofauna. J Aquat Ecosyst Stress Recov 7:57-74

Ellis JI, Cummings V, Hewitt J, Thrush S, Norkko A (2002) Determining effects of suspended sediment on condition of a suspension feeding bivalve (Atrina zelandica): results of a survey, a laboratory experiment and a field transplant experiment. J Exp Mar Biol Ecol 267:147-174

Foster G, Carter L (1997) Mud sedimentation on the continental shelf at an accretionary margin-Poverty Bay, New Zealand. NZ J Mar Freshw Res 40:157-173

GESAMP (Joint Group of Experts on the Scientific Aspects of Marine Pollution) (1994) Anthropogenic influences on sediment discharge to the coastal zone and environmental consequences. UNESCO-TOC, Paris

Gray JS (1997) Marine biodiversity: patterns, threats and conservation needs. Biodivers Conserv 6:153-175

Griffiths GA, Glasby GP (1985) Input of river-derived sediment to the New Zealand continental shelf. I. Mass. Estuar Coast Shelf Sci 21:773-787

Hewitt JE, Cummings VJ, Ellis JI, Funnell G, Norkko A, Talley TS, Thrush SF (2003) The role of waves in the colonization of terrestrial sediments deposited in the marine environment. J Exp Mar Biol Ecol 290:19-47

Hicks DM (1994) Land-use effects on magnitude-frequency characteristics of storm sediment yields: some New Zealand examples. In: Olive LJ, Loughran RJ, Kesby JA (eds) Variability in stream erosion and sediment transport. International Association of Hydrological Sciences Press, Wallingford, p 395-402

Hicks DM, Gomez B, Trustrum NA (2000) Erosion thresholds and suspended sediment yields, Waipaoa River Basin, New Zealand. Water Resour Res 36:1129-1142

Hunt L (2002) An X-radiographic study of the October 2000 Po River flood deposit, Italy. Master of Science in

Editorial responsibility: John Gray (Contributing Editor), Oslo, Norway
Oceanography, Oregon State University, Corvalis, OR

Lohrer AM, Thrush SF, Gibbs MM (2004a) Bioturbators enhance ecosystem function through complex biogeochemical interactions. Nature 431:1092-1095

Lohrer AM, Thrush SF, Hewitt JE, Berkenbusch K, Ahrens M, Cummings VJ (2004b) Terrestrially derived sediment: response of marine macrobenthic communities to thin terrigenous deposits. Mar Ecol Prog Ser 273:121-138

McKnight DG (1969) A recent, possibly catastrophic burial in a marine molluscan community. NZ J Mar Freshw Res 3: $177-179$

Norkko A, Thrush S, Hewitt J, Cummings V and 5 others (2002) Smothering of estuarine sandlfats by terrigenous clay: the role of wind-wave disturbance and bioturbation in site-dependent macrofaunal recovery. Mar Ecol Prog Ser 234:23-41

Peterson CH (1985) Patterns of lagoonal bivalve mortality after heavy sedimentation and their paleoecological significance. Paleobiology 11:139-153

Shaffer JA, Parks DS (1994) Seasonal variations in and observations of landslide impacts on the algal composition of a Puget Sound nearshore kelp forest. Bot Mar 37:315-323

Snelgrove PVR (1999) Getting to the bottom of marine biodiversity: sedimentary habitats. BioScience 49:129-138

Thrush SF, Dayton PK (2002) Disturbance to marine benthic habitats by trawling and dredging-implications for marine biodiversity. Annu Rev Ecol Syst 33:449-473

Thrush SF, Hewitt JE, Norkko A, Cummings VJ, Funnell GA (2003) Macrobenthic recovery processes following catastrophic sedimentation on estuarine sandflats. Ecol Appl 13:1433-1455

Thrush SF, Hewitt JE, Cummings VJ, Ellis JI, Hatton C, Lohrer AM, Norkko A (2004) Muddy waters: elevating sediment input to coastal and estuarine habitats. Frontiers Ecol Environ 2:299-306

Wheatcroft RA (2000) Oceanic flood sedimentation: a new perspective. Cont Shelf Res 20:2059-2066

Whitlatch RB, Lohrer AM, Thrush SF, Pridmore RD, Hewitt JE, Cummings VJ, Zajac RN (1998) Scale-dependent benthic recolonization dynamics: life stage-based dispersal and demographic consequences. Hydrobiologia 375/376: $217-226$

Submitted: May 10, 2005; Accepted: August 10, 2005 Proofs received from author(s): December 15, 2005 